\title{
Certain Physical Characterization into Composite Leaf Fibres of Agave Americana L
}

\author{
Saravanan D* \\ Department of Textile Technology, Bannari Amman Institute of Technology, India
}

*Corresponding author: Saravanan D, Department of Textile Technology, Bannari Amman Institute of Technology, Sathyamangalam, 638 401, India submission: 㘹 February 13, 2018; Published: 㘹 May 23, 2018

\begin{abstract}
Newer natural fibres are often explored due to eco-friendliness and availability of such fibres in the specific regions. Agave americana L fibres, extracts from the leaves of the Agave plant, represent the naturally available cellulosic fibres with interesting properties. Voids, in the cross-sections of the fibres, were observed in the microscopic analysis and the fibres exhibit high degree of crystallinity. Bundle fibres extracted from the leaves exhibit low elongation with high tensile stress compared to many non-apparel fibres and the moisture, thermal properties similar to that of any other cellulosic fibres.
\end{abstract}

Keywords: Degree of crystallinity; Fibre length, Moisture regain, Tenacity, Transitions, Thermal degradation

\section{Introduction}

Agave americana $L$ fibres are extracted from leaves of the Agave americana $L$, a plant native to Mexico and Caribbea, characterized by fleshy, rigid, hard leaves growing directly out from the central stalk. Leaves of the Agave species grow up to a length of 1 to $1.5 \mathrm{~m}$; consist of bundles of fibres, which in turn made up of many single fibres held together randomly [1-5]. Single fibres, with ribbon like structure, separated from bundles of fibres by acid treatment and alkali boil, have been characterized extensively in past $[3,4]$ and the present study is an attempt to characterize the bundle fibres of the Agave americana L.
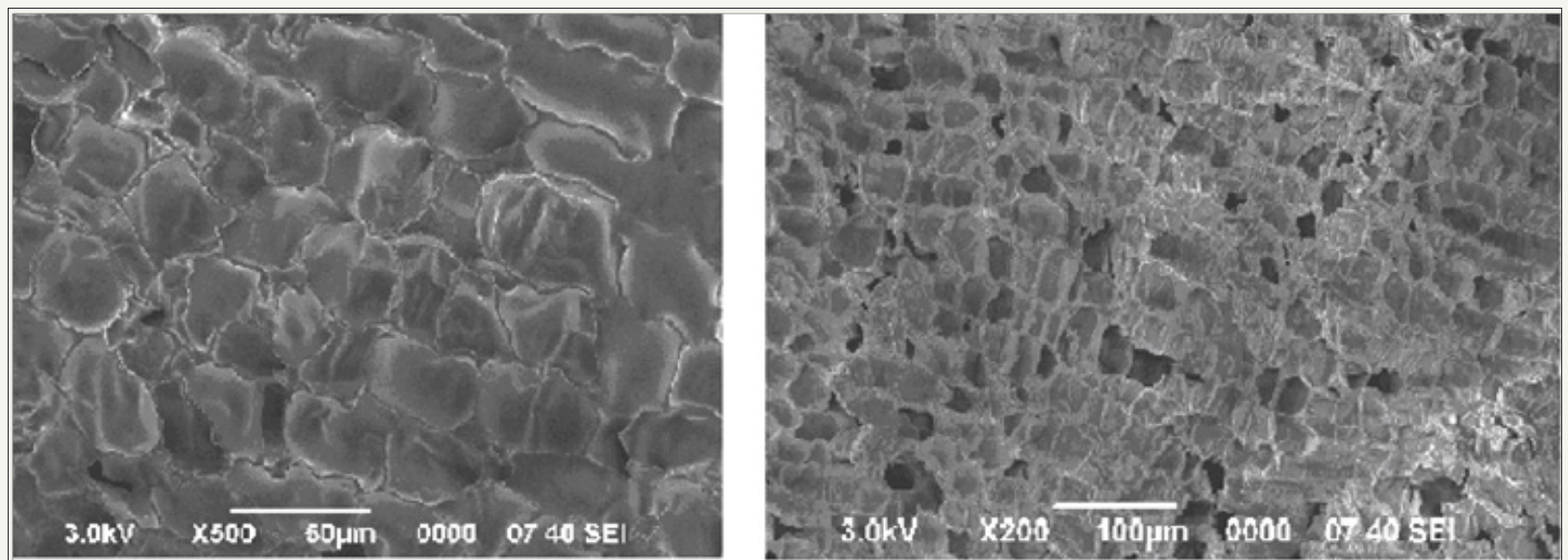

Figure 1: Cross section of Agave americana $L$ bundle fibres.

Fibres originally obtained from the leaf extracts were yellowishgreen in colour, which became pale yellow on washing with water. Total extractable impurities, measured as per IS 9068, were present in the fibres to the extent of $5.37 \%$, of which $2.78 \%$ extractable impurities was obtained from ethanol extraction and $2.59 \%$ from carbon tetrachloride. Fibre diameter, measured using optical microscope, revealed values starting from $110 \mu \mathrm{m}$ and upwards with an average of $140 \mu \mathrm{m}$, many fold higher than the individual fibres $[4,6]$. Cross sections of the fibres obtained using scanning electron microscope (Figure 1) showed the presence of voids all over the structure, formed perhaps during evaporation of cell sap while separation and drying process of fibres [4]. 
Density values of the fibres, at constant temperature showed the values in the range of $1.047 \mathrm{~g} / \mathrm{cc}$ to $1.098 \mathrm{~g} / \mathrm{cc}$, which is low compared to many cellulosic fibres and single fibres (1.36g/ cc) separated from bundle fibres [3,6]. Highest linear density of bundles fibres calculated, as per ASTM D157, was 105 dtex and the lowest value was $\sim 43$ dtex with an average of 63 dtex. Agave americana $L$ bundle fibres exhibited higher moisture regain value at $12.50 \%$, with the moisture content of $11.10 \%$, following ASTM D2654-89a. Less amounts of hydrophobic materials present in the fibres as shown in the solvent extraction, also could have facilitated the absorption and retention of moisture in the fibres.

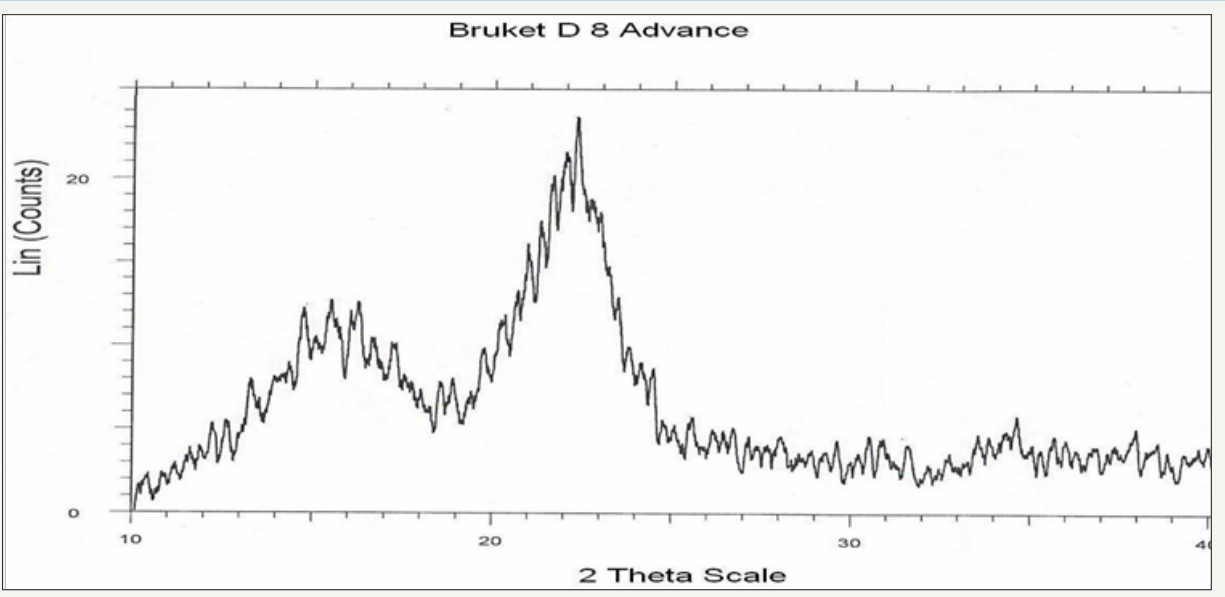

Figure 2: X-ray diffraction of powder sample.

Powder XRD of Agave americana $L$ fibres carried out for equatorial reflections, showed two prominent peaks at $15 \mathrm{o}$ and 22.5o (Figure 2), obviously due to (101) and (002) reflections [7]. Degree of crystallinity was found to be $\sim 50.3 \%$ with the crystallite thickness $\sim 23.30$ Ao at $2 \theta=22.50$. Hydration in the leaves during the growth of the fibres could have hindered the growth of the crystallites and crystalline regions in the fibres. Similar stress-strain curves were obtained in all dry and wet specimens regardless to diameter of the fibres. After reaching the yield point, with an initial modulus $28.67 \mathrm{cN} /$ tex at $1.5 \%$ extension, stress levels increased linearly up to the point of break, under dry condition. In the case of wet condition, the tenacity values were found to vary from $38 \%$ to $79 \%$ of the dry tenacity values (Table 1 ).

Table 1: Tenacity and elongation under dry and wet conditions.

\begin{tabular}{|c|c|c|}
\hline Property & Dry Condition & Wet Condition \\
\hline Tenacity (cN/tex) & 85.52 & 49.10 \\
\hline CV\% of Tenacity & 48.40 & 41.50 \\
\hline Elongation (\%) & 8.80 & 9.17 \\
\hline CV\% of Elongation & 35.50 & 27.30 \\
\hline
\end{tabular}

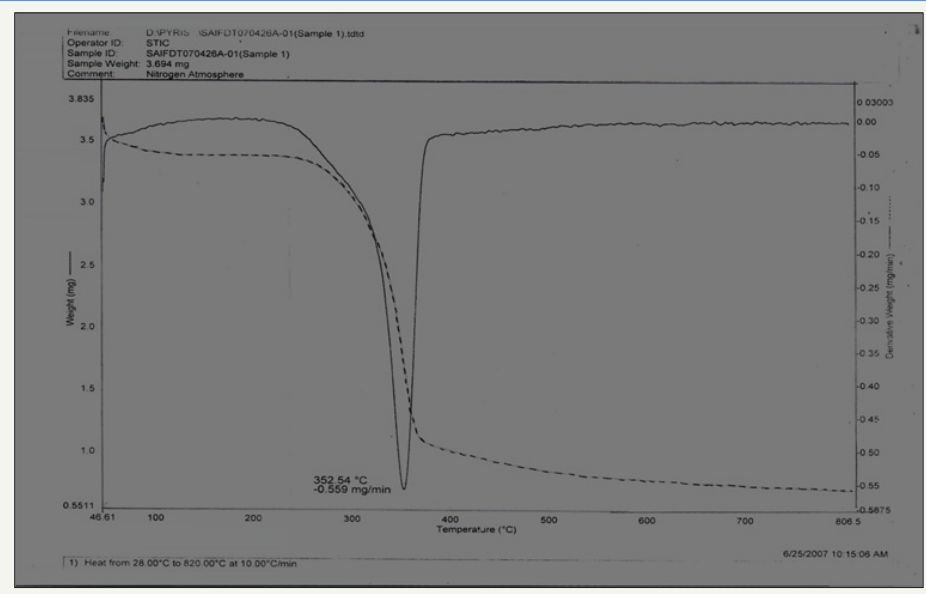

Figure 3: TGA-DTGA curves of Agave americana $L$ fibre sample.

In thermo gravimetric analysis, typical weight losses were observed in the temperature ranges of 600 to $100 \mathrm{oC}, 300$ $385 \mathrm{oC}$, leading to final decomposition (Figure 3). Between the temperatures $100 \mathrm{oC}$ to $300 \mathrm{oC}$, the sample was found to be highly stable, comparable to many cellulosic fibres like viscose rayon, cotton linters, and mercerized cotton fibres [8]. At the end of the scan, higher amount of char type of residues were found $\sim 19.0 \%$ Maximum rate of degradation in sample weight, $15.15 \%$, was observed at a temperature of $352 \mathrm{oC}$, which was incidentally the temperature slightly above the half decomposition (T1/2) i.e. $348 \mathrm{oC}$. 
Thermogram obtained in the differential scanning calorimetry did not show any prominent transitions up to $500 \mathrm{oC}$. An endothermic peak near $100 \mathrm{oC}$ related to the evaporation of the moisture present in the specimen, supplementing the thermo gravimetric analysis.

\section{Conclusion}

Presence of voids in the leaf fibres of Agave americana $L$ fibres resulted in the very low density values in spite of high degree of crystallinity. Higher surface area created by the voids also is believed to facilitate moisture absorption, together with low extractable hydrophobic impurities. Thermal degradation of fibres were found to happen at similar temperatures as that of other cellulosic fibres and the high degree of crystallinity, possibly, hinder degradation of fibres at low temperatures.

\section{References}

1. Datta PC (1971) Karyological anatomy of fiber development in the leaves of Agave americana L. Annals of Botany 35: 421-427.
2. Rasheed S, Dasti AA (2003) Quality and mechanical properties of plant commercial fibres. Pakistan Journal of Biological Sciences 6: 840-843.

3. Chaabouni Y, Drean JY, Mshahli S, Sakli F (2006) Morphological characterization of individual fiber of Agave americana L. Textile Research Journal 76: 367-374.

4. Msahli S, Drean JY, Sakli F (2005) Evaluating the fineness of Agave americana L fibres. Textile Research Journal 75: 540-543.

5. Thamae T, Baillie C (2007) Influence of fibre extraction method, alkali and silane treatment on the interface of Agave americana waste HDPE composites as possible roof ceilings in Lesotho. Composite Interfaces 14: 821-836.

6. Msahli S, Sakli F, Drean JY (2006) Study of textile potential of fibres extracted from Tunisian Agave americana L. Auxtex Research Journal 6: 9-13.

7. Alexander LE (1969) X ray diffraction methods in polymeric science. Wiley Interscience, London, UK.

8. Sefain MZ, El-Kalyoubi SF (1984) Thermo gravimetric studies of different celluloses. Thermochimica Acta 75(1-2): 107-113.
Creative Commons Attribution 4.0 International License

For possible submissions Click Here

\section{Submit Article}

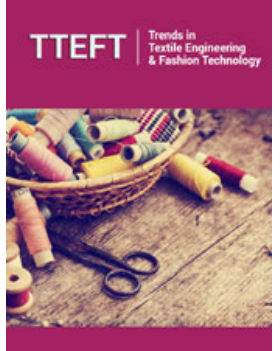

Trends in Textile Engineering \& Fashion Technology

\section{Benefits of Publishing with us}

- High-level peer review and editorial services

- Freely accessible online immediately upon publication

- Authors retain the copyright to their work

- Licensing it under a Creative Commons license

- Visibility through different online platforms 